\title{
PARA UMA CRÍTICA DA RAZÃO PSICOMÉTRICA ${ }^{1}$
}

\author{
Maria Helena Souza Patto
}

\begin{abstract}
mas além disso há o aberto, a noite ruiva, as unidades da desmedida, a qualidade de palhaço e de funâmbulo e de sonâmbulo do cidadão médio [...]; a escola fará a parte dela, e o exército e os padres, mas isso que eu chamo de enguia ou via láctea pernoita na memória

racial [...], e por isso a revolução no seu momento, $[. .$.$] por isso as primeiras etapas do$ reencontro do homem inteiro. E, contudo, aí se emboscam outra vez a Dama da Ciência e seu séquito, a moral, a cidade, a sociedade.
\end{abstract}

Julio Cortázar

Encaminhar para diagnóstico os alunos que não correspondem às expectativas de rendimento e de comportamento que vigoram nas escolas é um anseio de professores, técnicos e administradores escolares que um número crescente de psicólogos tem ajudado a realizar.

Como regra, o exame psicológico conclui pela presença de deficiências ou distúrbios mentais nos alunos encaminhados, prática que terá resultados diferentes de acordo com a classe social a que pertencem: em se tratando de crianças da média e alta burguesia, os procedimentos diagnósticos levarão a psicoterapias, terapias pedagógicas e orientação de pais que visam a adaptá-las a uma escola que realiza os seus interesses de classe; no caso de crianças das classes subalternas, ela termina com um laudo que, mais cedo ou mais tarde, justificará a sua exclusão da escola. Nesse caso, a desigualdade e a exclusão são justificadas cientificamente (ou seja, com pretensa isenção e objetividade) por meio de explicações que ignoram a sua dimensão política e se esgotam no plano das diferenças individuais de capacidade.

Pesquisas recentes sobre a escola pública de primeiro grau, como instituição social que só pode ser entendida no interior das relações sociais de produção em vigor na sociedade que a inclui, têm mostrado com frequência que o rendimento escolar não pode ser entendido sem que se leve em conta a relação entre a lógica das práticas escolares e as atitudes e comportamentos comumente tomados como "indisciplina", "desajustamento", "distúrbio emocional”, "hiperatividade", "apatia”, "disfunção cerebral mínima", "agressividade", "deficiência mental leve" e tantos outros rótulos caros a professores e psicólogos.

I Versão originalmente publicada em Patto (2000). 
Quem já esteve em uma escola pública e conversou com professores e técnicos a respeito da repetência sabe que, em sua maior parte, eles ainda têm uma visão preconceituosa da pobreza, portadores que são de um traço profundo da cultura dominante brasileira: a desqualificação dos pobres. Submetidos a más condições de trabalho, os professores costumam procurar bodes expiatórios para a incompetência pedagógica; formados no interior de concepções científicas tradicionais do fracasso escolar (engendradas e divulgadas desde o começo do século pelo movimento escolanovista), segundo as quais a marginalidade social é expressão de deficiências biopsicológicas individuais, aderem com facilidade a uma visão medicalizada das dificuldades de escolarização das crianças das classes populares.

Importante notar que essas opiniões também comparecem no discurso dos próprios psicólogos, embora de forma mais sutil, uma vez que traduzidas em termos científicos. Só a título de exemplo: um psicanalismo recente, fundado na concepção winnicottiana de "mãe suficientemente boa", tem explicado os altos índices de repetência escolar e atos ilegais entre crianças e jovens das classes trabalhadoras a partir do pressuposto de que as mulheres pobres são "mães não suficientemente boas" para promover a saúde mental de seus filhos. Essa versão inclui a dimensão política só na aparência: embora faça referência à pobreza, naturaliza-a ao reduzi-la a uma questão de falta de recursos materiais, deixando de lado as questões da ideologia e do poder e sua relação com a rebeldia, de um lado, e a natureza do aparato jurídico-policial, de outro. Aparato, é preciso ressaltar, assessorado pela própria Psicologia, que participa da formação das penas, fornecedora que é de laudos, não raro, portadores de forte acento moralista, além de reducionistas, pois fechados no plano do indivíduo e da família tomados como abstrações².

Silvia Leser de Mello (1999) diz isso com muita propriedade:

Tarefa urgente nos cursos de Psicologia é não partir do pressuposto de que as famílias pobres são indignas, denunciando e tentando reverter o abuso cometido contra elas sempre que são transformadas em responsáveis pela violência, pela criminalidade, e até, no extremo, pelos desajustes do país. É preciso dizer e tornar a dizer que a famosa "família desorganizada ou desestruturada" é um estereótipo que culpabiliza as vítimas. A aplicação indiscriminada de modelos familiares normativos a grupos familiares que são divergentes deles pode causar muito mal, acentuando as diferenças e transformando-as em estigmas. A mulher que cuida sozinha de seus filhos não é um monstro. Ela e a criança são uma familia. Este é o entendimento do Eca (Estatuto da Criança e do Adolescente) e é preciso fazê-lo chegar aos alunos na universidade. Um bom

2 Exemplo da interpretação dos comportamentos ilegais de crianças e jovens pobres encontra-se em Cohen, Ferraz e Segre (1996). 
psicólogo deve começar seu trabalho pelo respeito ao cliente e à sua dignidade. Respeitar significa aplicar-se na compreensão das diversidades e no acatamento das divergências.

A "teoria" da carência cultural deu continuidade à explicação da "marginalidade" social e legal nos termos biopsicológicos que vieram no bojo da Psicologia científica. Gerada na década de 1970 nos Estados Unidos da América, no interior do movimento por direitos civis das minorias raciais, é portadora de estereótipos e preconceitos sociais trazidos pelo "racismo científico" a respeito dos pobres e continua a marcar presença nos meios em que se planeja e faz a educação escolar primária no Brasil. Tomada como base de medidas administrativas e pedagógicas que buscam saídas técnicas para o beco em que se encontra a educação pública elementar, só tem contribuído para o aprofundamento da má qualidade da escola que se oferece ao povo, na medida em que justifica o barateamento do ensino e a realização da profecia segundo a qual os pobres não têm capacidade suficiente para o sucesso escolar.

As práticas de diagnóstico de alunos encaminhados por escolas públicas situadas em bairros pobres constituem verdadeiros crimes de lesa-cidadania: laudos sem um mínimo de bom senso e senso de ridículo produzem estigmas e justificam a exclusão escolar de quase todos os examinados, reduzidos a coisas portadoras de defeitos de funcionamento em algum componente da máquina psíquica.

A estereotipia da linguagem utilizada, a mesmice das frases, conclusões e recomendações trazem-nos à mente a imagem de um carimbo: os laudos geralmente apresentam uma criança abstrata, sempre a mesma, desenhada com técnicas limitadas e um ou outro chavão teórico. $\bigcirc$ fato de invariavelmente aprovarem a crença dos educadores de que há algo errado com o aprendiz mostra uma significativa convergência das visões técnico-científica e do senso comum. Tudo se passa como se professor e psicólogo se aliassem no pressuposto de que o aluno que não se adapta às imposições escolares é portador de alguma anormalidade, restando apenas consultar os testes, para supostamente diagnosticá-la.

Como técnicas de exame psicológico que fundamentam as conclusões, esses laudos mencionam testes de avaliação da inteligência, da personalidade e das chamadas habilidades especiais, em conformidade com a fragmentação da psique em instâncias e funções que caracteriza a Psicologia objetivista ${ }^{3}$. Muitas vezes, um teste de inteligência construído nos Estados Unidos da América para testar recrutas durante a Primeira Guerra Mundial é suficiente para a emissão de veredictos, prática que preocupa, não só pela precariedade, como pela ignorância de reflexões há muito publicadas sobre o assunto. Em 1989, em um evento organizado pelo Conselho Regional de Psicologia, Vera Stella Telles (1989, p.231-232) disse com todas as letras:

3 Recentemente, o psicólogo norte-americano Howard Gardner, ao contestar a concepção monolítica de inteligência presente no QI, opondo-lhe o conceito de inteligência múltipla, deu continuidade ao projeto da Psicologia de parcelamento do psiquismo humano, em nome de seu estudo em moldes objetivos. Sobre os males dessa segmentação, veja Maia (1998). 
Perguntam-me também o que acho das baterias de testes para delimitar as classes especiais, e de se aplicar testes de QI em crianças de cinco e seis anos para entrarem em uma escola de primeiro grau. E mais: alguns professores pedem ao psicólogo que teste as crianças que dão trabalho, que atrapalham as tarefas escolares. Eu acho bastante oportunas essas perguntas. Quando uma sociedade, uma cultura, começa a tentar classificar até crianças, para formar a classe ideal, nós estamos, no meu entender, à beira da falência. [... $] \bigcirc$ psicólogo tem que se negar a isso. Em primeiro lugar, uma criança é o que é. É fruto de uma família e a família está ligada ao todo social; isso é o espelho de nosso momento e não uma coisa a ser jogada na lata do lixo.

Telles se refere aos exames psicológicos que se restringem à avaliação do indivíduo. Nos laudos psicológicos enviados às escolas, poucas vezes a bateria é mais completa, o que, como veremos, pode não melhorar em nada a situação, pois o que temos são dados segmentados que esfacelam o avaliado e são interpretados de modo a confirmar a anormalidade pressuposta.

A revelação desse estado de coisas gera discussões cheias de percalços a respeito dos testes psicológicos. $\bigcirc$ assunto é difícil, por vários motivos: porque põe em evidência a má formação dos psicólogos; porque o uso de testes para fins psicodiagnósticos é, por lei, privativo desses profissionais e está no centro de sua identidade, o que faz com que seu questionamento provoque ameaça de perda de um importante ponto de referência; porque a crítica se faz a partir da filosofia materialista histórica, objeto de desconfiança e desconhecimento de grande parte dos psicólogos; e porque a inércia também está presente no corpo docente que forma psicólogos. Mas a dificuldade maior de realizar esse debate certamente vem do predomínio técnico na formação de psicólogos, em geral, e dos que se dedicam à aplicação de testes, em particular.

A crítica dos testes de inteligência tem se voltado sobretudo aos conteúdos dos itens e às próprias condições de aplicação: aponta-se o predomínio do conhecimento escolar em suas provas; a falta de clareza das "regras do jogo", como é o caso da cronometragem das respostas sem o conhecimento do examinando ou o fato de as perguntas terem significados e funções diversas no contexto familiar, escolar e de avaliação psicológica, o que confunde as crianças durante o processo de avaliação ${ }^{4}$; a influência da motivação do examinando para realizar as tarefas previstas; as consequências de uma história de fracasso escolar sobre o desempenho nos testes; a relação examinador-examinando, modificadora de ambos, principalmente quando se faz presente a verticalidade das relações de classe; a familiaridade dos testandos com materiais e tarefas, usos e costumes, normas e valores, crenças e expectativas contidos nos testes. Esta última restrição refere-se ao viés cultural que eles contêm. Este viés é frequentemente mencionado, mas como entendê-lo em

4 Sobre a questão do significado das perguntas feitas por adultos em diferentes contextos, veja Cagliari (1997). 
chave esclarecedora? Ele não se resume a mera atribuição de peso maior a uma entre as diversas culturas existentes em uma mesma sociedade: é instrumento de hegemonia cultural, procedimento de imposição da cultura dominante em detrimento das demais e faz parte do autoritarismo das elites - em suma, é um recurso poderoso de dominação de classe que se vale da justificação ideológica da desigualdade social.

Somadas, todas essas críticas a conteúdos e procedimentos de aplicação configuram os testes de QI como artimanhas do poder, que preparam armadilhas aos avaliados, que podem acabar vítimas de resultados que não passam de artefato do próprio instrumento de medida. Mas a crítica às técnicas de exame psicológico pode ser mais funda e refletir sobre o critério de normalidade que lhes serve de base e as próprias concepções de inteligência e personalidade a partir das quais são construídos.

Atento às relações de poder nas sociedades de classes, Michel Paty (1998, p. 160) define o QI unicamente como indicador cultural de integração social, do grau de adesão às normas e valores dominantes. Um item de uma escala de inteligência infantil, no qual se pergunta, com o objetivo de avaliar a capacidade de compreensão, por que é melhor dar dinheiro a uma instituição de caridade do que a um pedinte na rua pode ilustrar isso com perfeição: as respostas corretas devem fazer menção à segurança proporcionada por essas instituições quanto à aplicação correta do dinheiro, em contraste com o mau uso que poderá ser feito pelo pedinte. Ora, tais respostas pressupõem pelo menos três coisas: ausência de crítica social, preconceito contra os pobres e união cega à ética e ao padrão de sociabilidade que fundam a filantropia - ou seja, participação em um "modo de pensar" que dispensa o pensar.

De uma perspectiva foucaultiana, o exame psicométrico faz parte do olhar panóptico, uma nova forma de investigação que substitui o inquérito. ${ }^{5}$ Segundo Frayze-Pereira (1989, p.209):

Não se trata mais de saber se algo foi feito ou por quem foi feito, mas se o que foi feito é normal ou não, correto ou não segundo valores hegemônicos. Não se trata mais de inquérito, mas de exame, isto é, de vigilância, exercida pelo professor, pelo médico, pelo supervisor, pelo juiz, pelo psicólogo. Exame que é exercício de poder, uma vez que, ao mesmo tempo que vigia, produz um saber sobre os vigiados, saber esse que se organiza em torno da norma. $\bigcirc$ que se quer saber é o grau de submissão dos indivíduos aos diferentes poderes, motivo pelo qual se aperfeiçoam as técnicas de observação, classificação, comparação e analise de comportamentos.

É isso que preocupa Leser de Mello (1999, p. I 49) quando reafirma a importância de fazer chegar aos cursos de Psicologia uma saudável desconfiança do valor dos testes de inteligência e personalidade:

5 Veja, entre outras obras, Foucault (1987). 
[...] deveria fazer parte do ensino levar os alunos a compreenderem a qualidade do poder que a "especialização" Ihes confere: encerrar no inferno da Febem um jovem, negar uma adoção ou facilitar a "'guarda' de crianças, afastar filhos de pais, lançar uma criança na carreira, sem esperança, das classes especiais, contribuir para a morte civil da criança ou jovem contraventor.

Theodor Adorno também fez a crítica da concepção de inteligência presente nos testes de QI. No mundo do desenvolvimento técnico, diz ele, a adequação exigida não se limita aos comportamentos diretamente envolvidos no exercício profissional; todo o pensamento, e não só seus segmentos exigidos profissionalmente, está agora submetido ao controle social. $\bigcirc$ desempenho do pensamento inteiro converte-se em solução de tarefas impostas de fora, torna-se training, pois os objetos sobre os quais incide tornam-se barreira diante das quais tem de se mostrar em forma. $\bigcirc$ pensamento que perdeu autonomia tem de provar o tempo todo que está em boas condições de treino, mesmo onde não há nada a resolver. Nesse contexto, qualquer modalidade de pensamento que queira estabelecer uma relação não pragmática com o real é vista como vã e indiferente ao social. Em consonância com a concepção neo-positivista de conhecimento (na qual este comparece dividido em empiria acumulada e formalismo lógico), na avaliação científica da atividade intelectual "todo pensamento transforma-se [...] em um questionário lúdico, seja do grau de informação, seja da aptidão", isto é, um inventário do que se sabe e em teste da capacidade de pensar segundo os cânones da lógica formal. Se assim é, na avaliação quantitativa do pensamento, as respostas certas têm de já estar registradas em algum lugar. O pensamento hoje se reduziu à sua integração ao aparato social - ou seja, o pensamento instrumental passou a ser o próprio paradigma do pensamento humano. Adorno (1992, p. 172-173) resume essa redução ao afirmar que "o instrumentalismo, a mais recente versão do pragmatismo, há muito deixou de ser uma mera questão de aplicação do pensamento: ele é o a priori de sua própria forma”. Os testes de inteligência lidam, portanto, com a inteligência pragmatizada, a razão encarcerada em sua forma instrumental, mas a maioria dos psicólogos não sabe disso e toma os altos escores como indicadores de superioridade de uma abstrata inteligência humana.

A mesma crítica vale para as técnicas de avaliação da personalidade; no caso dos testes projetivos, muitas vezes psicólogos alheios à questão da vida danificada e suas implicações psíquicas valem-se de dois ou três jargões, sempre os mesmos, para "interpretá-los", e tomam como natural o que é social; como social (em seu sentido funcionalista) o que é político; como dores do crescimento, sofrimentos causados por situações sociais de humilhação ${ }^{6}$; como saúde, o que é limitação. Muitas vezes, procedimentos vagamente inspirados em uma psicanálise vulgar repetem concepções já problematizadas em leituras críticas dos textos técnicos de Freud: a civilização que impõe privações é aceita de modo

6 Gilberto Safra, comunicação pessoal. José Moura Gonçalves Filho (1998, p. I I-67) vem realizando um estudo original do sentimento de humilhação como sofrimento político. 
acrítico ou pelo menos resignado; em nome do princípio de realidade, justificam-se os sacrifícios psicológicos dos indivíduos, sem submeter o próprio princípio à crítica se tem por objetivo promover a adaptação social do paciente, animá-lo ao trabalho e à felicidade nas circunstâncias sociais dadas, não criticadas (Adorno, 1975, p.34). Ao entender assim indivíduo e sociedade, "acabam conservando o que dá alento à adaptação social" (p.24-25).

Os exames da personalidade se valem ingenuamente do conceito de normalidade e tomam como indicadores de saúde psíquica comportamentos que, segundo Adorno, "só podem ser realizados ao preço da mais profunda mutilação". As pessoas normais têm que reprimir não só desejos e conhecimentos, mas todos os sintomas que na época burguesa decorrem da repressão; assim, ter saúde psíquica em nossa época é bloquear a fuga para a doença, sem alterar em nada sua etiologia. É por isso que Adorno afirma: "a doença própria da nossa época consiste precisamente no que é normal” (Adorno, 1975, p.50). Os que constroem técnicas de avaliação da personalidade e as aplicam em geral não sabem disso; permanentemente às voltas com homens coisificados, não têm instrumentos teóricos para percebê-lo, o que os leva a incluir traços psíquicos reificados em seus critérios de saúde mental.

Este é o objeto da crítica às técnicas de exame psicológico: elas não erram quando buscam tipos psíquicos, mas quando consideram alguns deles - exatamente os que indicam adesão pura e simples às exigências sociais - como paradigmáticos de saúde mental. É essa a contribuição mais importante que a reflexão de Adorno sobre os tipos e síndromes tem a dar à Psicologia. Ele não defende os instrumentos psicodiagnósticos oficiais nem as tipologias arbitrárias e irracionais das teorias de personalidade da Psiquiatria e da Psicologia; ao banirem dos testes de inteligência qualquer resposta indicativa de pensamento crítico ou ao tomarem como saudável a personalidade mutilada, essas teorias (e os instrumentos que alimentam) promovem uma perversa redução psicológica do objeto de estudo e, assim, fazem parte das práticas sociais que danificam a vida pela reiteração do dano inaugural presente nas relações de produção. As práticas de exame são, portanto, parte integrante das condições históricas atuais, motivo pelo qual não faz sentido isentar todo e qualquer instrumento de avaliação do psiquismo de seus efeitos reificadores. A redução do objeto é devida às condições históricas, das quais os métodos de exame psicológico que naturalizam o homem participam, a menos que se entenda a história em termos idealistas.

É importante trazer para dentro da Psicologia a reflexão da teoria crítica sobre a perda da fluência da vida psíquica, motivo pelo qual, no interior dessa teoria, justifica-se uma concepção de personalidade fundada em tipos psicológicos. Mas é preciso lembrar também que, quando faz a crítica da crítica das tipologias, Adorno fala em diferentes modalidades de tipificação teórica da personalidade: de um lado, as tipologias de "natureza essencialmente não dinâmica, 'anti-sociológica' e quase-biológica [...] opõem-se diretamente à teoria do nosso trabalho e a seus resultados empíricos"; de outro, a tipificação que orienta a pesquisa empírica e as interpretações teóricas do estudo da personalidade autoritária, do qual ele faz parte em sua fase norte-americana. Para definir esta última, adverte: 
O fator que torna sempre plausível o enfoque tipológico não é de caráter estático-biológico, mas pelo contrário, dinâmico-social. $\bigcirc$ fato de a sociedade humana estar dividida em classes até a atualidade afeta algo mais do que as relações externas dos homens. Na alma do indivíduo ficam impressos os vestígios da repressão social. [...]. É muito provável que isso aconteça num grau superior em nossa cultura padronizada de massa do que em épocas anteriores. [...] Quem critica a tipologia não deve esquecer que um grande número de pessoas já não é - melhor dizendo, nunca foi - "indivíduo", no sentido que a palavra tem na filosofia tradicional do século dezenove. Se existem os que pensam em rótulos, isto se deve unicamente a que processos sociais subjugantes, obscuros, padronizados, "rotulantes", que praticamente não deixam ao "indivíduo" liberdade de ação nem oportunidade de verdadeira individuação, determinam este modo de pensar. Desta forma, estabelece-se um novo ponto de partida para a tipologia. Temos razões para buscar tipos psicológicos porque o mundo em que vivemos esta tipificado e "produz" diferentes "tipos" de pessoas. É só identificando os aspectos estereotipados do homem moderno, e não negando sua existência, que se pode contrapor à tendência perniciosa a classificação e ao agrupamento gerais (Adorno, 1965, p.697-698, grifos nossos).

O que não quer dizer que a teoria crítica tenha afirmado, de modo puro e simples, a morte do sujeito. ${ }^{7}$

É perigoso, portanto, afirmar, sem matiz, que a redução do objeto não se deve ao método, mas às condições históricas, pois uma coisa são escalas construídas para investigar os danos sociais da personalidade e desvelar a sua redução; outra são as técnicas convencionais de investigação da inteligência e personalidade que, baseadas no mito de psique como estrutura orgânica que nada deve ao social e na identificação entre saúde mental e adaptação, tomam a redução historicamente construída como natural e não como parte do arsenal de práticas sociais que repõem a reificação, ou seja, que integram os poderosos mecanismos sociais de reprodução do existente.

7 Em nome de Adorno e Horkheimer, tem-se afirmado, de modo dogmático e plano, a morte do sujeito nas sociedades da cultura padronizada de massas. No entanto, são muitas as passagens nos escritos desses dois filósofos em que essa afirmação é cuidadosa e matizada. A própria ênfase da teoria no esclarecimento racional como forma de evitar que Auschwitz se repita traz implícita a possibilidade do pensamento crítico nessas sociedades. Mesmo que nas sociedades tecnológicas atuais a maioria das pessoas esteja, em maior ou menor grau, reificada, é preciso perguntar se "a fetichização é algo absoluto e definitivo, se é possível manipular o homem tanto quanto se queira, se os homens são manipuláveis infinitamente em qualquer direção, se não existe sempre um ponto limite, um limes no qual deixam de ser objetos e se transformam em sujeitos" (Heller, 1972, p.99). Se não o fizermos, corremos o risco de cair no mesmo impasse do Dogmatismo, que, ao afirmar a impossibilidade do conhecimento, impugna a si mesmo. Se for verdade que é ingenuidade romântica falar em subjetividade e em intersubjetividade (pois pressupõe a existência de sujeitos onde eles inexistiriam), resta indagar sobre o estatuto mesmo desta afirmação: se anunciada por um homem reificado (ja que todos o seriam nas sociedades atuais) ela é fruto da impossibilidade de pensamento crítico nessa sociedade, tanto quanto as que afirmam o contrário. 
Não é demais reafirmar: as concepções de inteligência e personalidade que fundamentam os testes e as maneiras de pensar dos que os engendram, aplicam e avaliam baseiam-se em concepções 'quase-biológicas', 'anti-sociológicas' da psique, razão pela qual não se pode defendê-las, nem os seus instrumentos de medida, a partir dos argumentos que fundamentam a tipologia e as escalas que integram o estudo clássico da personalidade autoritária, no qual se buscaram deliberadamente aspectos básicos do caráter fascista.

Em relação aos testes de personalidade usuais entre psicólogos, resta ainda a tarefa de discutir se eles têm acuidade para captar a segmentação historicamente imposta à subjetividade humana, uma vez que não foram construídos nem são interpretados desta perspectiva. Pode-se perguntar se não estão fundamentados em teorias que pressupõem a totalidade do caráter ou em uma "fé harmonística na unidade da pessoa", inimaginável nas atuais sociedades massificadas; pode-se perguntar também sobre seu compromisso com o que Adorno chamou de "jargão da autenticidade", autenticidade impossível que está no núcleo de concepções existenciais-humanistas.

Desnecessário dizer, não se trata de "culpar" os testes psicológicos, pois a culpa não é atributo de objetos e de seres não-pensantes; não se trata também de "demonizá-los", como se só eles fossem construções técnicas ou teóricas. Toda teoria é uma interpretação, e todo instrumento de pesquisa ou diagnose é uma construção, mas como vimos, há construções e construções: teorias e técnicas diferem quanto à acuidade crítica dos pressupostos que as constituem e ao papel social que desempenham. Há concepções que produzem ficções sobre os homens, falam de homens abstratos, encobrem a realidade e somam com a desumanização; há concepções que as desvelam, em nome do compromisso expresso com a vida justa. As tipologias estático-biológicas e os testes que elas informam estão no primeiro caso; as dinâmico-sociais, no segundo. Essa diferença tem de ser marcada, motivo pelo qual tachar de ilusão romântica qualquer crítica a qualquer tipologia é fazer retroceder a contribuição trazida pela reflexão adorniana sobre tipos e síndromes.

Discutir os testes não é pôr em confronto gostos e opiniões pessoais, muito menos transformar o debate em rinha ou ringue para divertir a plateia. $\bigcirc$ que está em pauta não são os testes em si mesmos, mas uma discussão teórica de caráter muito mais amplo: o da própria concepção de ciência, homem e sociedade que lastreia uma Psicologia que está na base da criação de instrumentos para fins de avaliação quantitativa e classificação de indivíduos e grupos e tem sido qualificada como positivista, instrumental, objetivista e fisicalista (Lepoldo e Silva, 1997). Ou seja, a chave da crítica aos testes e às concepções de homem que os engendram está na discussão da própria concepção de ciência que Ihes dá existência. Se assim é, a conclusão bastante usual entre participantes desses debates de que "fulano não gosta de testes" prova que a discussão teórica não aconteceu.

Para que haja um debate fecundo, é preciso que ambos os lados tenham um mínimo de clareza a respeito do lugar teórico a partir do qual elaboram seus argumentos. Os que defendem a mensuração do psiquismo e os laudos psicológicos precisam conhecer não só os pressupostos filosóficos das técnicas que adotam, mas também os fundamentos 
da crítica, sem o que não podem contra-argumentar. $\bigcirc$ mesmo vale para os que fazem a crítica: é preciso que conheçam a base teórica da Psicologia psicométrica e normativa e dominem o arcabouço teórico com o qual se debruçam sobre ela para desvelar a sua razão. Sem isso, a comunicação torna-se impossível e o que se tem é um estéril e absurdo diálogo de surdos, do qual é melhor ausentar-se.

No interior desse debate, questões teóricas provocam com frequência respostas pragmáticas. Diante da crítica da coisificação do sujeito operada pelos testes, alega-se que o problema não está neles, mas na imperícia dos que os aplicam e redigem laudos; diante da proposta de substituí-los por outras formas de conhecer as pessoas, alega-se a necessidade de diagnósticos rápidos; diante da crítica que os desvela como instrumentos que justificam cientificamente a desigualdade e a exclusão escolar, menciona-se a possibilidade de usá-los para incluir, como nos raros casos em que, a partir de resultados de QI, crianças são retiradas das classes especiais e enviadas a classes comuns. Note-se que, neste argumento, a superação do caráter classificador-excludente dos testes é ilusória, pois em verdade continua-se a afirmar que, em função dos resultados obtidos, é legítimo classificar crianças para fins de inclusão ou exclusão em espaços escolares diversos. Movendo-se nos limites do senso comum ou do pensamento cotidiano, esses raciocínios tomam por verdadeiro o que é útil e não saem do lugar.

Poder-se-ia pensar que o pragmatismo que povoa os argumentos dos psicólogos é mera consequência de sua má formação teórica. No entanto, não se trata disso: "o pragmatismo da ciência não é elemento derivado, que a ela se acrescentaria. Há uma intencionalidade pragmática originária" no modelo objetivista de Ciência (Leopoldo e Silva, 1997, p.22). A alegação de cientificidade dos testes e da Psicologia comparece com frequência como resposta ao seu questionamento. Mas a afirmação de seu estatuto científico, como se isso pusesse um ponto final ao debate, revela que os que fazem a Psicologia geralmente passam ao largo da crítica filosófica e sociológica contemporânea das Ciências Humanas, crítica essa que traz à luz a reificação dos homens quando identificados com o objeto das Ciências Naturais e declarados passíveis de serem conhecidos por meio dos mesmos métodos.

Aprisionada em sua circunstância de especialização, a Psicologia faz parte do "cientificismo parcelador e coisificador do conhecimento", que produz "modalidades segmentadas do conhecimento" (Martins, 1978, p. 20). O que os psicólogos podem fazer nas condições históricas atuais é aproximar-se das teorias que lhes permitam pensar criticamente as condições em que a especialidade que praticam se fez e se faz como ciência e profissão. Dizendo de outra maneira, os psicólogos precisam pensar o seu pensamento, tarefa impossível sem a perspectiva histórico-crítica.

Fazer a crítica da Psicologia (e da psicometria) é situar o conhecimento que ela produz, é

ir à sua raiz, definir os seus compromissos sociais e históricos, localizar a perspectiva que o construiu, descobrir a maneira de pensar e interpretar a vida social da classe que apresenta esse conhecimento como universal. [...] A perspectiva crítica pode [...] descobrir toda a amplitude do que se acanha limitadoramente sob 
determinados conceitos, sistemas de conhecimento ou métodos (Martins, 1977, p.2).

Fazer a crítica da Psicologia é desvendar a lógica do modo de produção capitalista em suas teorias e técnicas.

Frayze-Pereira (1989, p.227) diz o mesmo a partir de um outro ângulo e com outras palavras:

Como é possível resistir a essa potência de uma sociedade inteiramente fundada sobre as práticas de vigilância, entre as quais o psicodiagnóstico estaria absolutamente colocado? [... . Pelo exercício da crítica $[. .$.$] pela apreensão crítica do real [ ... ]que leva em conta$ o processo de constituição concreta da realidade que estou pretendendo compreender. [...]. Fico em dúvida se o psicodiagnóstico como tal resiste a essa postura crítica, no momento mesmo em que se realiza, ou se a condição do exercício do psicodiagnóstico não é o fato de a crítica ser deixada de lado.

A reflexão sobre a Psicologia só se realiza quando se busca a perspectiva de classe a partir da qual foi construída. Dizer que o ângulo de visão proporcionado pelo compromisso de classe faz parte do arcabouço das teorias é dizer que os interesses de classe são constitutivos de conceitos, sistemas de conhecimento e métodos; significa, portanto, dizer que as dimensões política e epistemológica do conhecimento são inseparáveis. Sendo assim, crítica não é implicância, opinião ou ataque pessoal a teorias e métodos, não é recusa de uma modalidade de conhecimento em nome de outra. "O procedimento crítico é aquele que incorpora, ultrapassando, determinado conhecimento" (Martins, 1978, p.45). Quando se diz que o conhecimento objeto da crítica é incorporado por ela, está-se afirmando que a crítica não o recusa, mas vai em busca de sua gênese; quando se diz que ela o ultrapassa, o que se quer dizer é que, desvendando a sua razão - e só assim - pode superá-lo. Para fazer a crítica da psicometria (e da Psicologia que a contém) é preciso, em primeiro lugar, buscar sua origem teórico-política, ou seja, analisar o momento histórico da constituição das classificações valorativas inerentes a uma Psicologia normativa. Proceder assim significa concebê-la não como um engano, mas como conhecimento que tem a sua razão, "uma razão anti-histórica, mas historicamente determinada" (Martins, 1978, p.45).

Noções naturalizadas e matematizadas de diferenças individuais e grupais de capacidade psíquica foram elaboradas a partir de condições sócio históricas determinadas que é preciso desvendar. Foi desta perspectiva que se pôde fazer a crítica da cruzada psicométrica do começo do século XX e da "teoria" da carência cultural; foi a partir dela que se pôde desvelar a visão de mundo da burguesia triunfante oitocentista incrustada na crença da distribuição meritocrática das pessoas pelos lugares sociais, concepção que preside as classificações valorativas de inteligência e personalidade; foi ela que permitiu perceber que o conceito ideológico de aptidão natural faz parte dos processos que reprodutivos da sociedade capitalista. Enfim, é desta perspectiva totalizadora e histórica que se pode 
perceber que o conhecimento não é neutro e pode ter consequências que escapam às boas intenções de quem o produz ${ }^{8}$.

conhecimento materialista histórico não aspira à neutralidade. Nas Teses Contra Feuerbach (1845), Marx (1978, p.49-53) explicitou a natureza engajada de sua teoria; na décima-primeira tese ele diz: "Os filósofos se limitaram a interpretar o mundo; diferentemente, cabe transformá-lo.". O compromisso com a transformação do mundo e a dignidade do homem é princípio constitutivo, marca de nascença de seu arcabouço teórico e móvel da reflexão de Marx sobre o conhecimento e a condição humana sob o modo capitalista de produção.

Tendo como referência a filosofia marxista, Martins (1978, p.45) afirma: "só o compromisso com a transformação da sociedade pode revolucionar o conhecimento.". Partindo da teoria crítica frankfurtiana, Segundo Leopoldo e Silva (1 997, p.25), "a teoria tradicional supõe a possibilidade de uma descrição neutra da realidade, mesmo que esta realidade seja psicológica, social ou histórica, isto é, mesmo naquilo que se refere ao homem", ao passo que "a teoria crítica não pode deixar de considerar a gênese social dos problemas, as situações reais nas quais a ciência é empregada e os fins perseguidos." A consideração das finalidades sociais do conhecimento está, portanto, no cerne destas concepções das Ciências Humanas, o que permite afirmar que nelas a linha que separa Ciência e Ética perde a nitidez?

O compromisso humano-genérico está no cerne da obra de Marx e é constitutivo de sua antropologia e teoria do valor. Nos Manuscritos econômico-filosóficos, o conceito de alienação está no centro da análise da natureza da atividade produtiva, da relação do trabalhador com os produtos do seu trabalho e da lógica perversa na qual "o homem (o trabalhador) só se sente livremente ativo em suas funções animais - comer, beber e procriar, ou no máximo também em sua casa e no embelezamento dela -, enquanto em suas funções humanas se reduz a um animal." (Marx, 1970, p.94). Não por acaso, O Capital começa com a discussão sobre o fetichismo da mercadoria, em que os objetos materiais (as mercadorias) aparecem dotados naturalmente de valor, enquanto as relações de trabalho entre os produtores aparecem sob a forma de relações entre os produtos de seu trabalho. Não por acaso, a frase que abre esse texto fala do predomínio de coisas: "A riqueza das sociedades em que domina o modo capitalista de produção aparece como uma imensa coleção de mercadorias, e a mercadoria individual como sua forma elementar." (Marx, 1983, p.45). Em ambos os casos, Marx fala a partir de seu compromisso com os valores humanistas e denuncia a coisificação dos homens enquanto essência desse modo de produção. E o faz com fervor político e profundidade teórica'10.

8 Nos últimos anos, são muitas as histórias críticas da Psicologia. Veja, por exemplo, Paicheler (1992). Sobre a história do conceito ideológico de aptidões naturais, veja Bisseret (1978, p.30-67).

9 No pensamento frankfurtiano, a linha que separa a Ciência e a Arte como produtoras de conhecimento sobre a condição humana também é tênue. A este respeito, veja Buck-Morss (1977).

10 Ao tratar da questão do engajamento do cientista e da impossibilidade de uma ciência puramente objetiva e isenta de juízos de valor, Hobsbawm, depois de refletir sobre os limites além dos quais o compromisso político do pesquisador deixa de ser cientificamente legítimo, argumenta a favor do "engajamento objetivo", ou seja, do envolvimento do pesquisador até um ponto que não passe dos limites e não o transforme em presa de uma estrutura doutrinária ortodoxa, que não transforme sua produção em pseudociência a serviço da conveniência 
A crítica marxista do conhecimento que faz do sujeito um objeto tem origem na análise do fetichismo da mercadoria. É nela que se desvenda a maneira pela qual a forma econômica do capitalismo oculta as relações sociais que lhe são subjacentes; é nela que se fundamenta o desvelamento de uma forma de conhecimento que coisifica os homens ao se deter na aparência da realidade social, no que é imediatamente dado, em contraposição ao conhecimento que desvela sua essência, ou seja, a sua face ocultada. Dizendo de outro modo, de um ponto de vista materialista histórico, a origem dessa "ilusão de ótica" que transforma as coisas em entidades que se relacionam socialmente e as relações sociais entre os produtores em relações entre coisas está na forma assumida pelo trabalho sob o modo de produção capitalista. Cabe à teoria revelar a dimensão ocultada, ou seja, as relações sociais de produção. É, portanto, um enorme esforço teórico que possibilita a consciência de que o que aparece como natural é social; o que aparece como relação justa é exploração; o que aparece como resultado de deficiências individuais de capacidade é produto de dominação e desigualdade social historicamente engendradas.

Isto posto, três afirmações intimamente relacionadas, que se fazem presentes nos debates sobre os testes, precisam ser revistas: a primeira qualifica a crítica ético-política como fácil, superficial e inútil, pois, para realizá-la, supõe-se que bastaria "apresentar-se como marxista e em seguida tachar tudo de ideológico"; a segunda separa Ciência e Ética, a partir do pressuposto de que "Ciência é uma coisa e Ética, outra"; a terceira classifica a crítica ético-política como crítica externa do conhecimento, em contraposição à análise lógico-formal da correção do pensamento (tomado em si mesmo, independentemente de seu objeto), esta, sim, tida como verdadeira crítica interna.

Como vimos, o compromisso ético-político é constitutivo do edifício conceitual marxista, para o qual não há conhecimento sobre a realidade humana que seja descomprometido, o que significa que, no âmbito desta teoria, Ética e Ciência são indissociáveis. De outro lado, uma crítica que vai à raiz, desvela a realidade social ocultada pelo que é dado imediatamente e encontra no interior dos próprios conceitos e métodos a realização da necessidade de reprodução da ordem social capitalista não é fácil nem externa, mas a mais interna das críticas do conhecimento. A crítica Marxista é crítica

política. Segundo Hobsbawm, os intelectuais engajados (de qualquer tendência política) são os únicos dispostos a investigar problemas que o resto da comunidade intelectual não consegue investigar, inclusive por motivos ideológicos. Por isso, o engajamento faz a ciência avançar. A fertilização do campo científico por meio de desafios externos ao campo específico da pesquisa é benéfico ao avanço científico: estão aí os estudos sobre a escravidão e sobre a história do movimento trabalhista britânico para comprová-lo. Este benefício é tanto maior quanto mais a ciência se especializa e aprofunda a crença (em parte como reflexo do crescimento numérico de especialistas isolados em institutos, em parte como mistificação) de que o cientista é simples pesquisador da verdade acadêmica pura. A este respeito, ele diz: "quase não é preciso enfatizar os perigos e desvantagens óbvios da erudição engajada. $\bigcirc$ que é preciso enfatizar são suas vantagens menos óbvias. Elas precisam hoje ser particularmente enfatizadas porque a expansão e a dimensão sem precedentes da profissão acadêmica e a crescente especialização de cada disciplina e suas múltiplas subdisciplinas tendem cada vez mais a voltar o pensamento acadêmico para dentro de si mesmo". Isto faz com que os especialistas percam o sentido das implicações mais amplas dos temas que pesquisam, além de debilitar o incentivo a repensar a teoria, em vez de simplesmente desenvolvê-la com sofisticação técnica. Contra a tendência a desenvolver a engenhosidade intelectual por ela mesma a ao auto isolamento da academia, o "engajamento objetivo" é o mais poderoso procedimento de geração de novas ideias, perguntas e desafios externos às Ciências Humanas. Sem ele, o desenvolvimento delas estaria em risco. (Hobsbawm, 1998, p. I39- I52). 
imanente. Nesta linha de argumento, é válido proceder a uma inversão da classificação apontada acima e afirmar que a análise lógica do conhecimento produzido pelas Ciências Humanas e Sociais é crítica externa, mas não inócua, pois soma com o ocultamento do que é essencial na sociedade e repõe a tese da neutralidade do conhecimento, ocultamento e neutralidade próprios da filosofia positivista.

Na discussão sobre o fetichismo da mercadoria, está a origem do conceito de ideologia como conjunto de ideias que, por se deterem nas camadas aparentes do real, obscurecem a percepção do modo de ser da sociedade capitalista e resultam em percepção lacunar do objeto sobre o qual versam:

discurso ideológico é um discurso feito de espaços em branco, como uma frase na qual houvesse lacunas. A coerência desse discurso [...] não é uma coerência nem um poder obtido malgrado as lacunas, malgrado os espaços em branco, malgrado o que fica oculto; ao contrário, é graças aos brancos, graças às lacunas entre as suas partes, que esse discurso se apresenta como coerente. Em suma, é porque não diz tudo e não pode dizer tudo que o discurso ideológico é coerente e poderoso. [...] $\bigcirc$ discurso ideológico se sustenta, justamente, porque não pode dizer até o fim aquilo que pretende dizer. Se o disser, se preencher todas as lacunas, ele se autodestrói como ideologia. A força do discurso ideológico provém de uma lógica que poderíamos chamar de lógica da lacuna, lógica do branco (Chauí, 1981, p.21-22).

O que uma concepção da sociedade de classes como organização hierárquica baseada em diferenças individuais de aptidão (mensuráveis ou detectáveis por meio de testes psicológicos) não diz e não pode dizer sob pena de se autodestruir? $\bigcirc$ que os laudos psicológicos - por mais fiéis que sejam à técnica dos testes e aos princípios lógicos do pensamento correto sobre crianças que não conseguem se escolarizar na escola pública brasileira - não dizem e não podem dizer sob pena de autodemolição? Não dizem muitas coisas: que o comportamento escolar dessas crianças não é um "em si", mas parte integrante de uma instituição de ensino, cuja lógica é imprescindível conhecer se se quiser entender o significado desse comportamento; que em uma sociedade de classes o Estado defende os interesses das classes que detêm o poder econômico e o poder cultural; que a escola para o povo tem, no caso brasileiro, uma história marcada pelo descaso do Estado; que uma política educacional marcada por esse descaso e equívocos tecnicistas sucateou a rede pública de escolas; que a burocratização da escola eliminou uma avaliação fecunda da qualidade do ensino oferecido; que a política salarial desestimula os professores que, frustrados e desrespeitados, repassam o desrespeito aos usuários da rede de escolas públicas; que a maior parte dos professores é concessionária do preconceito, da raiva e do desrespeito pelos pobres, traço profundo de uma sociedade de origem escravocrata em que a classe dominante sempre primou pela violência e pelo arbítrio; que a vida diária escolar concretiza tudo isso sob a forma de práticas e processos pedagógicos 
e administrativos produtores de dificuldades de ensino e aprendizagem dos bens culturais que cabe à escola transmitir, sobretudo aos alunos que dependem inteiramente dela para aprendê-los; que as relações pessoais na escola são via de regra autoritárias e produtoras de estigma, humilhação e exclusão; que a falta frequente de professores faz com que classes inteiras fiquem abandonadas por longos períodos, o que não impede que sejam, no ano seguinte, rotuladas como "fracas", substitutas das classes especiais; que todo esse processo é vivido com dor pelas crianças e as leva a danos psíquicos que os psicólogos entendem equivocadamente como causa das dificuldades escolares, operando uma inversão típica das ideias ideológicas: tomar os efeitos como causas; que os resultados alcançados nos próprios testes de inteligência dependem do histórico escolar do avaliado, que leva o aluno a reações negativas em situações de avaliação, à descrença quanto às suas capacidades diante do resultado obtido em testes que exigem informações que não podem ser esperadas de crianças que não tiveram o direito a uma escola de boa qualidade.

A tentativa de preencher essas lacunas não corrigiria os "enganos" dos laudos, tornando-os verdadeiros. Tudo isso levado em conta, eles seriam destruídos, baseados que estão na "lógica da lacuna" contida em um psicologismo que pressupõe que dificuldades de aprendizagem e adaptação escolar decorrem de distúrbios físicos ou psíquicos encerrados no indivíduo.

A consciência de que uma prática profissional limitada é uma necessidade histórica não é um convite a posturas fatalistas. No caso da Psicologia, não justifica a paralisia ou passividade em face das implicações éticas e políticas de seu exercício profissional. Se é verdade que uma proposta de substituição dos testes por outras formas de avaliação é perigosa - pois, facilmente incorporadas à realização das mesmas finalidades político-sociais, só reforçariam aquilo que criticam -, tal advertência não pode minimizar a atividade contida na postura crítica. A atividade de desvelamento pode sair da academia e ser incorporada a uma ação profissional orientada por valores positivos, ou seja, voltados para a realização da utopia do mundo humanizado. Como diz Paulo Freire:

[... ] utopia é unidade de denúncia e anúncio. A ação problematizadora junto a indivíduos e grupos, que tenha no horizonte a humanização dos homens, ao mesmo tempo que denuncia uma realidade desumanizante e os instrumentos ideológicos de sua manutenção (como o são muitas técnicas psicológicas de exame e terapia), anuncia uma realidade transformada e mantém aceso o sonho de uma vida mais humana. Quando se indagam sobre o mundo em que vivem e o lugar que nele ocupam, indivíduos e grupos defrontam-se com limites objetivos, impostos pelas condições históricas atuais, e obstáculos subjetivos que pedem entendimento para que sejam superados. E esses indivíduos e grupos passíveis de esclarecimento podem ser alunos e professores; estudantes de Psicologia, psicólogos e o público que demanda os seus serviços; grupos que se engajam em ações alternativas em instituições. 
E vale terminar com a insistência de Freire (1970) no restabelecimento da reflexão compartilhada:

[...] se os homens são estes seres da busca e se sua vocação ontológica é humanizar-se, podem, cedo ou tarde, perceber a contradição em que a "educação bancária" pretende mantê-los e engajar-se na luta por sua libertação. Um educador humanista, revolucionário, não há de esperar esta possibilidade. Não fazemos esta afirmação ingenuamente. Já temos afirmado que a educação reflete a estrutura do poder, daí a dificuldade que tem um educador dialógico de atuar coerentemente numa estrutura que nega o diálogo. Algo fundamental, porém, pode ser feito: dialogar sobre a negação do próprio diálogo.

Eis um bom começo para o diálogo teórico entre os psicólogos: dialogar sobre a impossibilidade do próprio diálogo. 


\section{REFERÊNCIAS BIBLIOGRÁFICAS}

Adorno, T. W. (1965). Tipos y síndromes. In Adorno, T. W et al. La personalidad autoritaria. Buenos Aires: Editorial Proyección.

. (1975). El psicoanalisis revisitado. In Adorno, T. W. et al. Teoria critica del sujeto. Madrid: Siglo XXI. (1 992). Minima Moralia. São Paulo: Ática.

Bisseret, N. (1978). A ideologia das aptidões naturais. In Durand, J. C. G (Org.) Educação e Hegemonia de Classe. As funções ideológicas da escola. Rio de Janeiro: Zahar.

Buck-Morss, S. (1977). The origin of Negative Dialetics: Theodor Adorno, Walter Benjamin and the Frankfurt Institute. Nova lorque: The Free Press.

Cagliari, L.C. (1997). O príncipe que virou sapo. In Patto, M.H.S. Introdução à Psicologia Escolar, São Paulo: Casa do Psicólogo.

Chauí, M.S. (1981). Cultura e democracia: o discurso competente e outras falas. São Paulo: Moderna.

Cagliari, L.C. (1985). O príncipe que virou sapo. Cadernos de Pesquisa, 55, 50-62.

Cohen, C., Ferraz, F. C, \& Segre, M. (Orgs.) (1996). Saúde Mental, Justiça e Crime. São Paulo: Edusp.

Cortázar, J. (1985) Prosa do Observatório. São Paulo: Perspectiva.

Frayze-Pereira, J. A. (1989). Psicodiagnóstico: instrumento de revelação? In Anais do I CONPSIC, São Paulo.

Foucault, M. (1987). Vigiar e Punir. Petrópolis: Vozes.

Freire, P. (1970). Pedagogia do oprimido (2 ed.). Rio de Janeiro: Paz e Terra.

Gonçalves Filho, J. M. ( 1998). Humilhação social: um problema político em Psicologia. Psicologia USP, 9(2), I I-67.

Heller, A. Sobre os papeis sociais. (1972). In O quotidiano e a História. Rio de Janeiro: Paz e Terra.

Hobsbawm, E. (1998). Engajamento. In Hobsbawm, E. Sobre História. Ensaios. São Paulo: Companhia das Letras. 
Leopoldo e Silva, F. ( 1 997). Conhecimento e razão instrumental. Psicologia USP, 8( I ), I I -3 I.

Martins, J.S. (1977). Introdução. In Foracchi, M.M., \& Martins, J.S. (Orgs.) Sociologia e Sociedade. Leituras de introdução à Sociologia. Rio de Janeiro: Livros Técnicos e Científicos. ( (1978). Sobre o modo capitalista de pensar. São Paulo: Hucitec.

MARX, K. (1970). Manuscritos econômicos e filosóficos. In Fromm, E. Conceito marxista do homem ( $5^{\mathrm{a}}$ ed.) Rio de Janeiro: Zahar.

. (1978). Teses contra Feuerbach. In Giannotti, J.A. (Org.) Manuscritos econômico-filosóficos e outros textos escolhidos ( $2^{\mathrm{a}}$ ed.). São Paulo: Abril Cultural (Coleção "Os Pensadores").

—. (1983). O capital: crítica da economia política (v. I). São Paulo: Abril Cultural.

Maia, A.F. (1998). Apontamentos sobre a Ética e individualidade a partir da Minima Moralia. Psicologia USP, (9)2, I 5 | - 177.

Mello, S.L.. (1999). Estatuto da criança e do adolescente: é possível torná-lo uma realidade psicológica?. Psicologia USP, I0(2), |39- I 5 |. Recuperado de: https://dx.doi.org/| 0.1590/ SOI03-65641999000200010.

Paicheler, G. (1992). L'invention de la Psychologie Moderne. Paris: Editions Harmattan.

Patto, M. H. S. Mutações do Cativeiro: escritos de psicologia e política. São Paulo: Hacker Editores/Edusp, 2000.

Paty, M. (1998). Os discursos sobre as raças e a ciência. Estudos Avançados, I2(33), 160.

Saviani, D. (1983). As teorias da educação e o problema da marginalidade. In Escola e democracia. São Paulo: Cortez.

Telles, V. S. ( I 989). Exposição na Mesa-Redonda Psicodiagnóstico: instrumento de revelação? In Anais do I CONPSIC. Editora do Conselho Regional de Psicologia: Brasilia. 